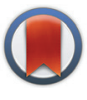

CrossMark $\leftarrow$ click for updates

Cite this: Dalton Trans., 2016, 45 9477

Received 30th March 2016, Accepted 10th May 2016

DOI: $10.1039 / c 6 d t 01226 d$

www.rsc.org/dalton

\title{
Boron difluorides with formazanate ligands: redox-switchable fluorescent dyes with large stokes shifts $\dagger$
}

\author{
M.-C. Chang, ${ }^{a}$ A. Chantzis, ${ }^{b}$ D. Jacquemin ${ }^{b, c}$ and E. Otten ${ }^{\star a}$
}

The synthesis of a series of (formazanate)boron difluorides and their 1-electron reduction products is described. The neutral compounds are fluorescent with large Stokes shifts. DFT calculations suggest that a large structural reorganization accompanies photoexictation and accounts for the large Stokes shift. Reduction of the neutral boron difluorides occurs at the ligand and generates the corresponding radical anions. These complexes are non-fluorescent, allowing switching of the emission by changing the ligand oxidation state.

\section{Introduction}

Fluorescent dyes have attracted increasing interest in various fields of modern research, including biological imaging, ${ }^{1}$ molecular probes, ${ }^{2}$ electroluminescent devices ${ }^{3}$ and photosensitizers. ${ }^{4}$ An ideal fluorescent dye presents high absorption coefficients and emission quantum yield, large Stokes shift, tuneable absorption/emission profiles, as well as high chemical and photochemical stability. Fluorescent dyes with large Stokes shift are more likely to show emission in the long wavelength region $(>600 \mathrm{~nm})$, which is desirable for applications in laser printing, information storage, displays and solar power conversion. ${ }^{5}$ Most importantly, fluorescent dyes emitting within the biological window $(650-900 \mathrm{~nm})$ are useful in bioimaging applications due to the small light scattering, low background emission and deep penetration into cells and tissues. ${ }^{6}$ Fluorescent dyes with small Stokes shifts usually suffer from self-quenching ${ }^{7}$ which limits the application in high concentration conditions and as solid state materials.

A large class of fluorescent dyes is based on the $\mathrm{BF}_{2}$ moiety bearing $N, N^{\prime}$ - or $N, O$-chelating ligands. ${ }^{8}$ Of these compounds, those with dipyrrin ligands, commonly known as BODIPYs (A in Chart 1), ${ }^{9}$ are the most popular systems due to their stability, high quantum yield and adaptable absorption/emission

\footnotetext{
${ }^{a}$ Stratingh Institute for Chemistry, University of Groningen, Nijenborgh 4, 9747 AG Groningen, The Netherlands. E-mail: edwin.otten@rug.nl

${ }^{b}$ Laboratoire CEISAM - UMR CNRS 6230, Université de Nantes, 2 Rue de la Houssinière, BP 92208, 44322 Nantes Cedex 3, France

'Institut Universitaire de France, 1, rue Descartes, 75005 Paris Cedex 5, France $\dagger$ Electronic supplementary information (ESI) available: Experimental section, X-ray data, computational methods. CCDC 1471287-1471289, 1471291-1471293 and 1471295. For ESI and crystallographic data in CIF or other electronic format see DOI: $10.1039 /$ c6dt01226d
}

profiles. The optical properties of the BODIPYs are tuneable by changing the $\mathrm{R}_{1}-\mathrm{R}_{7}$ substituents of the ligand backbone. ${ }^{9,10}$ In addition, the F-substituents of the boron center can also be replaced by aryl, alkyl, and alkoxide groups. ${ }^{11}$

Even though the largest documented Stokes shift for monoBODIPYs is $185 \mathrm{~nm},{ }^{12}$ for most of these systems the Stokes shift is usually less than $40 \mathrm{~nm}$. Recently, it was shown that incorporation of a triazole moiety on the $R_{3}$ position of the BODIPY framework results in a substantial increase in Stokes shift (up to $160 \mathrm{~nm}$ ). ${ }^{13}$ Also, chelates based on N,O donor atoms lead to dyes with relatively large Stokes shifts. ${ }^{8}$ In an alternative approach, the Stokes shift of fluorescent dyes can be increased by incorporation into an energy transfer fragment in which the energy absorbed by BODIPY unit is transferred to a second fluorophore. ${ }^{1 a, 4 a}$ A drawback, however, is that this strategy usually requires large synthetic efforts. In order to develop new fluorescent dyes, a variety of other $N, N^{\prime}$-chelating ligands have been proposed as shown in Chart 1. Boron difluoride complexes bearing $\beta$-diketiminate ligands (B)

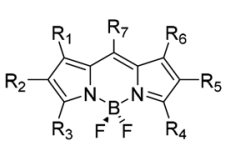

(A)

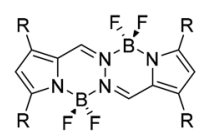

(D)

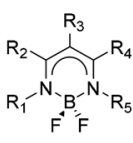

(B)

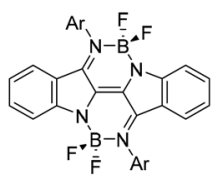

(E)

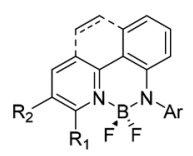

(C)

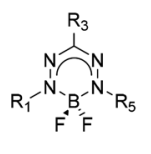

1
Chart 1 
exhibit strong absorption. ${ }^{14}$ In addition, compounds $\mathbf{B}$ show larger Stokes shifts $(c a .80 \mathrm{~nm})$ than BODIPYs. A de-symmetrized $\beta$-diketiminate analog, the anilido-pyridine (C) framework, was reported by the groups of Piers and Heyne in 2011 and presents large Stokes shifts of $90-120 \mathrm{~nm} .{ }^{15}$ Further modifications include 1,2-bis(pyrrolylmethylene) hydrazones (BOPHY) (D), ${ }^{16}$ and indigo- $N, N^{\prime}$-diarylamines (E) ${ }^{17} \mathrm{Com}^{-}$ pounds $\mathbf{D}$ are highly fluorescent $(\Phi>0.99)$ in solution with Stokes shifts around $40 \mathrm{~nm} .{ }^{16}$ In addition, they show emission in thin films and as solid powders. Compounds $\mathbf{E}$ are a class of redox-active and near-infrared dyes that show Stokes shifts of $30-70 \mathrm{~nm}^{17}$

Our group has been interested in the chemistry of formazanate ligands as nitrogen-rich, redox-active analogues of $\beta$-diketiminates, ${ }^{18,19}$ and we have previously communicated the synthesis of formazanate boron difluoride complexes. ${ }^{20}$ Concurrently, Gilroy and co-workers reported a series of similar compounds. ${ }^{21}$ In their work, the effect of ligand substituents on the optical properties was evaluated and the application of these compounds in electro-chemiluminescence ${ }^{22}$ and cell imaging ${ }^{23}$ was reported. Recently, Studer and co-workers used verdazyl radicals as "pro-fluorescent" radical probes. ${ }^{24}$

Here we describe the synthesis and characterization of (formazanate)boron complexes $\left(\mathrm{LBF}_{2}, \mathbf{1}\right.$, Scheme 1 ) as well as the corresponding 1-electron reduction products, the radical anions $\left[\mathrm{LBF}_{2}\right]^{0^{--}}\left(\mathbf{1}^{-\boldsymbol{}}\right)$, and discuss the impact of electronic and steric effects on both the optical and redox properties. We show that the neutral compounds $\mathbf{1}$ are fluorescent with large Stokes shifts, whereas in the radical anions $\mathbf{1}^{--}$the fluorescence is quenched.

\section{Results and discussion}

\section{Synthesis and characterisation of formazanate boron complexes}

Two synthesis methods for formazanate boron difluoride complexes have been reported by $\mathrm{us}^{20}$ and the Gilroy group, ${ }^{21}$ shown as path $A$ and path $B$ in Scheme 1, respectively. In the present contribution, both methods were used to yield the desired products in moderate to good yields (60-90\%). Using these methods, we prepared 9 (formazanate)boron difluoride compounds 1a-i. In addition, we synthesized two compounds in which the (formazanate) $\mathrm{BF}_{2}$ units are linked by phenylene moiety $(\mathbf{1 j}$ and $\mathbf{1 k})$. These compounds were recently reported by Gilroy and co-workers while this manuscript was in preparation. ${ }^{25}$ The formation of complexes 1 was confirmed by NMR spectroscopy, which shows diagnostic $1: 2: 1$ triplets in the ${ }^{11} \mathrm{~B}$ NMR spectra for the 4-coordinate $\mathrm{B}$ centres $(\delta-0.7$ to $-2.3 \mathrm{ppm}){ }^{19}$ In the ${ }^{19} \mathrm{~F}$ NMR spectra, $1: 1: 1: 1$ quartets between -145.6 and $-159.4 \mathrm{ppm}$ with $J_{\mathrm{B}-\mathrm{F}}=20-30 \mathrm{~Hz}$ are observed that are consistent with the presence of a $\mathrm{BF}_{2}$ moiety.

Single crystals suitable for X-ray diffraction analysis were obtained by recrystallization from heptane or hexane $(\mathbf{1 a}, \mathbf{b}, \mathbf{d}, \mathbf{h}$, i) $\dagger$ The molecular structure of $\mathbf{1 d}$ as a representative example is shown in Fig. 1 whereas Table 1 lists selected geometrical
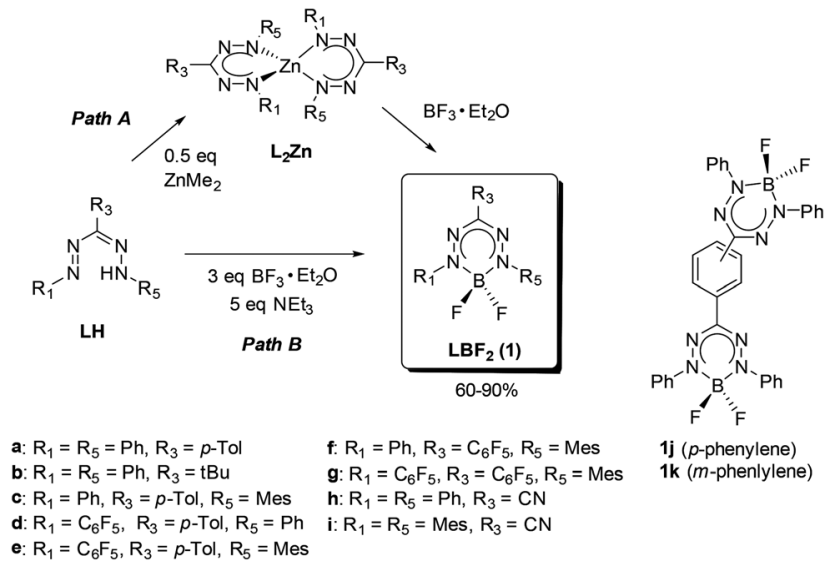

1j (p-phenylene) 1k (m-phenlylene)

$h: R_{1}=R_{5}=P h, R_{3}=C N$

e: $R_{1}=C_{6} F_{5}, R_{3}=p-T o l, R_{5}=M e$

Scheme 1 Indirect (path A) and direct (path B) methods for the synthesis of (formazanate)boron difluorides (1).

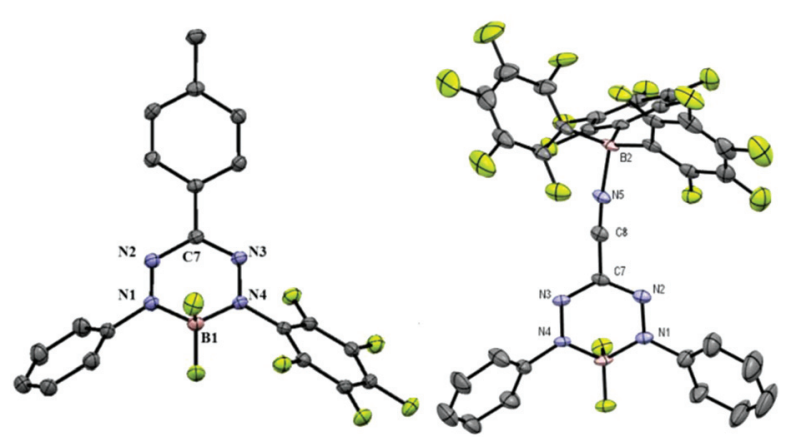

Fig. 1 Molecular structure of $1 \mathrm{~d}$ (left) and $1 \mathrm{hBCF}$ (right). Thermal ellipsoids are shown at $50 \%$ probability, and hydrogen atoms are removed for clarity.

parameters. The solid-state structures of all compounds show four-coordinate boron centres bound to the two terminal $\mathrm{N}$ atoms of a formazanate ligand to form a six-membered chelate ring, similar to those observed before. ${ }^{20,21}$ In most cases, the observed $\mathrm{C}-\mathrm{N}$ and $\mathrm{N}-\mathrm{N}$ bond lengths are in the range of 1.33-1.36 ̊ and 1.29-1.31 ̊, respectively, consistent with a delocalized ligand backbone. For the derivative with electronically dissimilar N-Ar substituents (1d, $\mathrm{R}_{1}=\mathrm{Ph}$ and $\left.\mathrm{R}_{5}=\mathrm{C}_{6} \mathrm{~F}_{5}\right)$ the data in Table 1 indicate a more localized bonding picture: the $\mathrm{N}-\mathrm{N}$ bond length adjacent to the electron-withdrawing $\mathrm{C}_{6} \mathrm{~F}_{5}$ group is significantly shorter (N1-N2: $\left.1.299(2) \AA\right)$ than that vicinal to the Ph substituent (N3-N4: 1.329(2) ̊). All the boron centres in $\mathbf{1 a}, \mathbf{1 b}, \mathbf{1 d}, \mathbf{1 h}$ and $\mathbf{1 i}$ show a distorted tetrahedral geometry, and the boron centre is significantly displaced from the formazanate backbone, with values ranging from $0.17-0.59 \AA$.

The $N$-aryl substituents are rotated out of the plane of the ligand backbone with dihedral angles ranging from $23-50^{\circ}$ for the compounds with unhindered Ar groups. The increased steric interactions in the $N$-Mes derivative 1i result, as expected, in a perpendicular orientation (dihedral angle of $88^{\circ}$ ). 
Table 1 Selected bond lengths $(\AA \AA)$ and bond angles $\left(^{\circ}\right)$ of $\mathrm{LBF}_{2}$ complexes (1) and their radical anions [1] $]^{\cdot-}$

\begin{tabular}{|c|c|c|c|c|c|c|c|c|c|}
\hline & $1 a^{e}$ & $1 b$ & 1d & $1 \mathrm{~h}$ & $1 \mathrm{i}$ & $1 \mathrm{hBCF}$ & {$[\mathrm{Na}(15-\mathrm{c}-5)]^{+}[\mathbf{1 c}]^{-d}$} & {$\left[\mathrm{Cp}_{2} \mathrm{Co}\right]^{+}[\mathbf{1 f}]^{\cdot-}$} & {$\left[\mathrm{Cp}^{*}{ }_{2} \mathrm{Co}\right]_{2}[\mathbf{1 j}]^{\cdot 2-}$} \\
\hline $\mathrm{N} 1-\mathrm{N} 2$ & $1.308(1)$ & \multirow[t]{2}{*}{$1.3177(12)$} & $1.2993(18)$ & $1.294(1)$ & \multirow[t]{2}{*}{$1.2931(15)$} & $1.307(4)$ & $1.376(3)$ & $1.374(2)$ & 1.3599(19) \\
\hline N3-N4 & $1.308(1)$ & & $1.3289(17)$ & $1.295(1)$ & & $1.300(4)$ & $1.370(3)$ & $1.356(2)$ & $1.3620(18)$ \\
\hline C7-N3 & $1.343(1)$ & $1.3394(12)$ & $1.329(2)$ & $1.340(2)$ & $1.3442(13)^{c}$ & $1.339(5)$ & $1.337(4)$ & $1.333(2)$ & $1.338(2)$ \\
\hline N1-B1 & $1.559(2)$ & \multirow[t]{2}{*}{$1.5523(15)$} & $1.577(2)$ & $1.573(2)$ & \multirow[t]{2}{*}{$1.5665(16)$} & $1.562(5)$ & $1.520(4)$ & $1.533(3)$ & $1.541(2)$ \\
\hline N4-B1 & $1.552(2)$ & & $1.548(2)$ & $1.580(2)$ & & $1.553(5)$ & $1.510(4)$ & $1.512(3)$ & $1.536(2)$ \\
\hline N1-B1-N4 & $102.40(9)$ & 100.15(11) & $101.52(12)$ & $105.87(9)$ & 103.76(14) & 104.4(3) & $107.4(2)$ & 108.49(17) & 108.46(13) \\
\hline & 42.00 & & 50.09 & 22.35 & & 44.39 & 65.05 & 83.44 & 13.23 \\
\hline
\end{tabular}

${ }^{a}$ Displacement of the B atom from the least-squares plane defined by N1, N2, N3 and N4. ${ }^{b}$ Angle between the planes defined by the N-Ar aromatic rings and the ligand backbone. ${ }^{c} \mathrm{C} 10-\mathrm{N} 2$ instead of C7-N2. ${ }^{d}$ Values reported for one of the two independent molecules. ${ }^{e}$ Data taken from ref. 20.

Compounds with cyano substituents $(\mathbf{1 h}, \mathbf{i})$ offer the possibility to influence the optical and redox properties by coordination of Lewis acids. To probe this, the $\mathrm{B}\left(\mathrm{C}_{6} \mathrm{~F}_{5}\right)_{3}$-adduct $\mathbf{1 h B C F}$ was prepared by stirring $\mathbf{1 h}$ with $\mathrm{B}\left(\mathrm{C}_{6} \mathrm{~F}_{5}\right)_{3}$ in toluene solution. Indicative of the formation of $\mathbf{P B C F}$ is the appearance of 3 additional resonances in the ${ }^{19} \mathrm{~F}$ NMR spectrum at $-134,-155$, and $-163 \mathrm{ppm}$ due to the $\mathrm{C}_{6} \mathrm{~F}_{5}$ rings. An X-ray structure determination (molecular structure in Fig. 1, pertinent bond distances and angles in Table 1) confirms the coordination of the Lewis acidic $\mathrm{B}\left(\mathrm{C}_{6} \mathrm{~F}_{5}\right)_{3}$ fragment to the cyano group.

\section{UV-Vis absorption and emission spectroscopy}

The optical properties of the formazanate boron complexes 1 were studied by UV-Vis absorption and emission spectroscopy in THF solution (Fig. 2 and Table 2). All compounds show

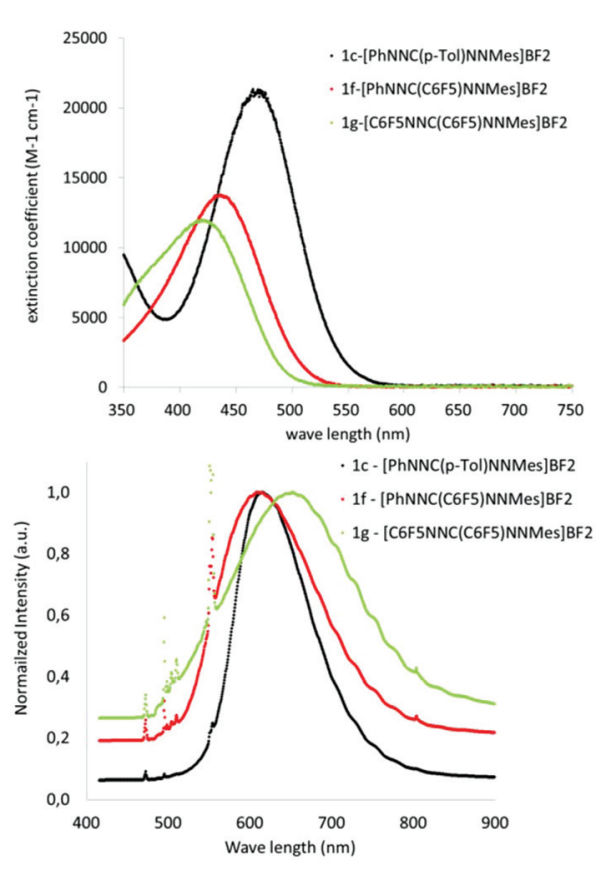

Fig. 2 UV-Vis absorption spectra (top) and normalised emission spectra (bottom) of $1 \mathrm{c}, 1 \mathrm{f}$, and $1 \mathrm{~g}$. Data were collected in $10^{-5} \mathrm{M}$ dry THF solution. The excitation wavelength of emission spectra is at $473 \mathrm{~nm}$.
Table 2 Optical properties of formazan boron complexes 1 in THF solution

\begin{tabular}{lllllll}
\hline & $\begin{array}{l}\lambda_{\max } \\
(\mathrm{nm})\end{array}$ & $\begin{array}{l}\varepsilon \\
\left(\mathrm{M}^{-1} \mathrm{~cm}^{-1}\right)\end{array}$ & $\begin{array}{l}\lambda_{\mathrm{em}}{ }^{c} \\
(\mathrm{~nm})\end{array}$ & $\begin{array}{l}\text { QY } \\
(\%)\end{array}$ & $\begin{array}{l}\text { SS } \\
(\mathrm{nm})\end{array}$ & $\begin{array}{l}\text { SS } \\
\left(\mathrm{cm}^{-1}\right)\end{array}$ \\
\hline $\mathbf{1 a}$ & 517 & 13736 & 641 & 0.2 & 124 & 3742 \\
$\mathbf{1 b}$ & 473 & 13220 & 643 & $<0.1$ & 170 & 5590 \\
$\mathbf{1 c}$ & 464 & 21306 & 617 & $<0.1$ & 153 & 5344 \\
$\mathbf{1 d}$ & 482 & 12523 & 640 & $<0.1$ & 158 & 5122 \\
$\mathbf{1 e}$ & 460 & 12139 & 610 & 0.1 & 150 & 5346 \\
$\mathbf{1 f}$ & 431 & 13702 & 612 & $<0.1$ & 181 & 6862 \\
$\mathbf{1} \mathbf{g}$ & 414 & 11852 & 650 & $<0.1$ & 236 & 8770 \\
$\mathbf{1 h a}$ & 489 & 25400 & 585 & 5 & 96 & 3356 \\
$\mathbf{1 h} \mathbf{h}^{a, b}$ & 502 & 30400 & 586 & 15 & 84 & 2855 \\
$\mathbf{1 h B C F}{ }^{b}$ & 502 & 20582 & 632 & 0.5 & 130 & 4098 \\
$\mathbf{1 i}$ & 428 & 9662 & 643 & 0.2 & 215 & 7812 \\
$\mathbf{1 j}$ & 523 & 30227 & 664 & 0.6 & 141 & 4060 \\
$\mathbf{1 k}$ & 508 & 16768 & 631 & 1.3 & 123 & 3837
\end{tabular}

${ }^{a}$ Taken from ref. $21 b .{ }^{b}$ Data collected in toluene solution. ${ }^{c}$ Excitation wavelength $=473 \mathrm{~nm}$.

medium to strong absorption bands with extinction coefficients between 9700 and $30200 \mathrm{~L} \mathrm{~mol}^{-1} \mathrm{~cm}^{-1}$ in the visible range of the spectrum (between 410 and $520 \mathrm{~nm}$ ). The spectral trends observed here are very similar to those described for bis (formazanate)zinc complexes. ${ }^{19}$ Introducing an electron-donating ${ }^{t}$ Bu-group (1b) instead of a $p$-tolyl moiety (1a) results in a blueshift of the absorption maximum (517 and $473 \mathrm{~nm}$ for $\mathbf{1 a}$ and $\mathbf{1 b}$, respectively).

In the case of the addition of an electron-withdrawing $\mathrm{C}_{6} \mathrm{~F}_{5^{-}}$ group (1f, $\mathbf{1 g}$ ) at the $\mathrm{R}_{3}$ position instead of a $p$-tolyl moiety (1c, 1e), the absorption maximum undergoes a blueshift as well (431 nm for 1f $v s .464 \mathrm{~nm}$ for $1 \mathrm{c} ; 414 \mathrm{~nm}$ for $1 \mathrm{~g} v s .460 \mathrm{~m}$ for 1e). Upon substitution of phenyl for mestiyl at the $R_{1}$ or $R_{5}$ positions, the $\lambda_{\max }$ is again blueshifted (489 nm for $1 \mathrm{~h} v s .428 \mathrm{~nm}$ for 1i). This likely results from the nearly perpendicular orientation of the mesityl group, which doesn't allow conjugation between the formazanate core and the side mestiyl ring, thereby limiting the size of the $\pi$-conjugated system. ${ }^{21 c}$ The introduction of the Lewis acid $\mathrm{B}\left(\mathrm{C}_{6} \mathrm{~F}_{5}\right)_{3}$ in $\mathbf{1 h B C F}$ surprisingly does not influence $\lambda_{\max }$. The UV-Vis absorption spectra of the di-formazanate system $(\mathbf{1} \mathbf{j}$ and $\mathbf{1} \mathbf{k})$ are very similar to $\mathbf{1 a}$ except for the expected $c a$. two-fold increase in molar extinction coefficients. 
Similar to other reported boron difluoride complexes, compounds 1 were shown to be emissive, with emission wavelengths $\lambda_{\mathrm{em}}$ in the $580 \mathrm{~nm}$ to $670 \mathrm{~nm}$ range in THF solution (Fig. 2). The reported (formazanate)boron difluoride complexes usually show large Stokes shifts $(100-150 \mathrm{~nm}) .{ }^{21,23}$ For most of the compounds reported here, the Stokes shifts are even larger $(>150 \mathrm{~nm})$. As an example, $1 \mathrm{~g}$ shows $\lambda_{\max }$ at $414 \mathrm{~nm}$ and $\lambda_{\mathrm{em}}$ at $650 \mathrm{~nm}$, a Stokes shift of $236 \mathrm{~nm}$ $\left(8770 \mathrm{~cm}^{-1}\right)$, which to the best of our knowledge is the highest value reported to date for this class of compounds. The large Stokes shift of compounds 1c-g might be due to the asymmetry in the substitution pattern of the ligands. The $\mathrm{B}\left(\mathrm{C}_{6} \mathrm{~F}_{5}\right)_{3}$ adduct $\mathbf{1 h B C F}$ shows a redshift in its emission spectrum $\left(\lambda_{\max }=\right.$ $632 \mathrm{~nm})$ relative to $\mathbf{1 h}(586 \mathrm{~nm})$, which increases the Stokes shift from $84 \mathrm{~nm}\left(4098 \mathrm{~cm}^{-1}\right)$ to $130 \mathrm{~nm}\left(4098 \mathrm{~cm}^{-1}\right)$ in toluene solution. These results suggest that the emission profile of (3-cyanoformazanate)boron difluoride complexes is tuneable via binding of Lewis acids. The phenylene-linked systems $\mathbf{1} \mathbf{j}$ and $\mathbf{1 k}$ show emission spectra that are redshifted and blueshifted, respectively, compared to those of the parent compound 1a, whereas the obtained quantum yields are higher.

\section{Cyclic voltammetry}

The redox chemistry of compounds $\mathbf{1}$ was studied by cyclic voltammetry $(\mathrm{CV})$ in tetrahydrofuran (THF) or 1,2-dichloroethane (DCE) solution under nitrogen atmosphere. All complexes show two (quasi)reversible redox processes corresponding to the formation of the radical anions $[1]^{\cdot-}$ and dianions $[1]^{2-}$. The results of cyclic voltammetry studies are summarized in Table 3. From these data it is apparent that the redox potentials of (formazanate) $\mathrm{BF}_{2}$ complexes can be altered over a wide range (up to $530 \mathrm{mV}$ ) by changing the substituents on the ligand framework. The measured redox-potentials correlate with the electron-donating ability of the $R_{3}$-substituent via inductive effects: an electron-donating $t$-butyl group (1b) induces a shift to more negative potential, while electron-

Table 3 Electrochemical Data $\left(\mathrm{V} v\right.$ s. $\left.\mathrm{Fc} / \mathrm{Fc}^{+}\right)$of $\mathrm{LBF}_{2} \mathrm{complexes}^{\mathrm{a}}$

\begin{tabular}{lll}
\hline & $\mathrm{LBF}_{2}{ }^{0 /-1}$ & $\mathrm{LBF}_{2}{ }^{-1 /-2}$ \\
\hline $\mathbf{1 a}$ & -0.98 & -2.06 \\
$\mathbf{1 b}$ & -1.08 & -2.21 \\
$\mathbf{1 c}$ & -1.19 & -2.34 \\
$\mathbf{1 d}$ & -0.85 & -1.99 \\
$\mathbf{1 e}$ & -1.01 & -2.26 \\
$\mathbf{1 f}$ & -1.02 & -2.25 \\
$\mathbf{1 g}$ & -0.84 & -2.17 \\
$\mathbf{1} \mathbf{h}$ & -0.66 & -1.83 \\
$\mathbf{1} \mathbf{h}^{b}$ & -0.65 & -1.76 \\
$\mathbf{1} \mathbf{h B C F}$ & -1.75 \\
$\mathbf{1 i}$ & -0.67 & -2.41 \\
$\mathbf{1 j}$ & -0.90 & -2.0 to -2.3 \\
$\mathbf{1} \mathbf{1}$ & -0.95 & -2.0 to -2.4
\end{tabular}

${ }^{a}$ Cyclic voltammetry experiments collected in THF solution $(1.5 \mathrm{mM}$ 1 and $0.1 \mathrm{M}\left[\mathrm{Bu}_{4} \mathrm{~N}\right]\left[\mathrm{PF}_{6}\right]$ as supporting electrolyte) at a scan rate if $0.1 \mathrm{~V} \mathrm{~s}^{-1}$. The data were referenced internally against the $\mathrm{Fc} / \mathrm{Fc}^{+}$ couple. ${ }^{b}$ Collected in DCE solution.

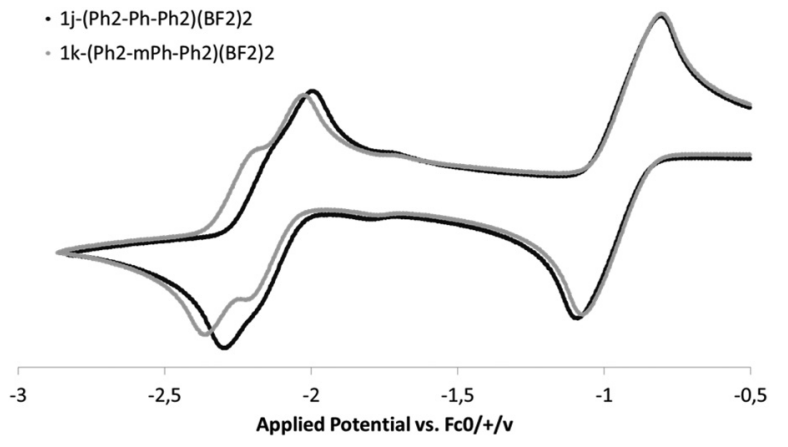

Fig. 3 Cyclic voltammograms of $1 \mathrm{j}$ and $1 \mathrm{k}$ recorded at $0.1 \mathrm{~V} \mathrm{~s}^{-1}$ in $1.5 \mathrm{mM}$ THF solution containing $0.1 \mathrm{M}$ tetrabutylammonium hexafluorophosphate.

withdrawing cyano (1h) or $\mathrm{C}_{6} \mathrm{~F}_{5}$ substituents (1f) result in an anodic shift, in comparison to $\mathrm{R}_{3}=p$-tolyl (1a). Changing the nature of the aromatic $N$-substituent(s) from $\mathrm{Ph}$ to an electronwithdrawing $\mathrm{C}_{6} \mathrm{~F}_{5}$ group (1a vs. 1d, 1c vs. 1e and 1f vs. 1g) shifts the redox potentials in the positive direction by 130-180 mV. As expected, substitution of a phenyl group for an electron-donating mesityl group (1a vs. 1c, $\mathbf{1 d} v s$. 1e and $\mathbf{1 h}$ vs. 1i) will shift the measured redox potentials to more negative values by around $240 \mathrm{mV}$. Surprisingly, coordination of the Lewis acid $\mathrm{B}\left(\mathrm{C}_{6} \mathrm{~F}_{5}\right)_{3}$ in $\mathbf{1 h B C F}$ induces only a marginal variation of the first redox potential from $-0.66 \mathrm{~V}(\mathbf{1 h})$ to $-0.67 \mathrm{~V}$ (1hBCF). This might be related to the high concentration of electrolyte: the $\mathrm{B}\left(\mathrm{C}_{6} \mathrm{~F}_{5}\right)_{3}$ group in $\mathbf{1 h B C F}$ does not interact strongly in the high ionic strength solvent system used for collecting the $\mathrm{CV}$ data. The $\mathrm{LBF}_{2}{ }^{\mathrm{O}-1}$ redox couple in $\mathbf{1 j}$ and $\mathbf{1 k}$ is observed at potentials similar to those in 1a, but corresponds to two sequential one-electron transfers as evidenced by the somewhat larger peak-to-peak separation in $\mathbf{1 j}$ and $\mathbf{1 k}$ $(0.268-0.287 \mathrm{~V}$, see Fig. 3$)$ than in $1 \mathrm{a}(0.222 \mathrm{~V})$. At more negative potential, $\mathbf{1} \mathbf{j}$ and $\mathbf{1 k}$ show two very close one-electron processes (between -2.0 and $-2.4 \mathrm{~V} v$ s. $\mathrm{Fc} / \mathrm{Fc}^{+}$). In the case of $\mathbf{1 j}$, these are poorly resolved but for $\mathbf{1 k}$ there are clearly two separate events, indicating that the two (formazanate) $\mathrm{BF}_{2}$ units in these phenylene-linked systems do not behave fully independently. ${ }^{26}$ Gilroy and co-workers described similar electrochemical data for these compounds in dichloromethane solution. While the 2-electron reduction products appeared unstable in dichloromethane solution, ${ }^{25}$ our data in THF suggest that in this solvent the products are stable and might be isolable (vide infra).

\section{Synthesis and characterisation of radical anions [1] $]^{-}$}

According to the $\mathrm{CV}$ data, the radical anions $[\mathbf{1}]^{\cdot-}$ are relatively stable and could be accessible chemically. Indeed, treatment of compounds 1 with $\mathrm{Cp}_{2}$ Co precipitated the dark green salts $\left[\mathrm{Cp}_{2} \mathrm{Co}\right]^{+}[\mathbf{1}]^{\bullet-}$. For the phenylene-linked bis(formazanate) systems $\mathbf{1} \mathbf{j}$ and $\mathbf{1 k}$, treatment with 1 equiv. of reducing agent resulted in precipitation of 0.5 equiv. of the corresponding diradical dianions $[\mathbf{1 j}, \mathbf{k}]^{\cdot 2-}$ and 0.5 equiv. of unreacted starting 
material instead of the radical anions $[\mathbf{1 j}, \mathbf{k}]^{--}$. This is presumably driven by the poor solubility of the dianionic products. In order to obtain crystalline products, a variety of reducing agents was used; a representative series $\left([\mathbf{1} \mathbf{a}]^{0^{--},{ }^{20}}[\mathbf{1 c}]^{--},[\mathbf{1} \mathbf{f}]^{{ }^{--}}\right.$ and $[\mathbf{1 j}]^{\cdot 2-}$ ) could be obtained in high yield with either $\mathrm{Cp}_{2} \mathrm{Co}^{+}$ $\left([\mathbf{1 a}]^{--}\right.$and $\left.[\mathbf{1 f}]^{\cdot-}\right), \mathrm{Na}\left(15-\right.$ crown-5) ${ }^{+}\left([\mathbf{1 c}]^{{ }^{--}}\right)$or $\mathrm{Cp}^{*}{ }_{2} \mathrm{Co}^{+}\left([\mathbf{1 j}]^{\cdot 2-}\right)$ as countercations. For all compounds, significant changes were observed in the metrical parameters of the reduced compounds in comparison to the neutral precursors. The most obvious change is the elongation of the $\mathrm{N}-\mathrm{N}$ bonds (from $1.30-1.31 \AA$ in 1 to $1.34-1.37 \AA$ in $[1]^{-0}$ ) due to population of a $\pi^{*}$-orbital that has $\mathrm{N}-\mathrm{N}$ antibonding character. ${ }^{19 a, 20}$ The $\mathrm{B}-\mathrm{N}$ bond lengths decrease upon reduction (1a: 1.559(2)/1.552(2) $\AA$ vs. $\left.[1 \mathrm{a}]^{--}: 1.532(3) / 1.536(3) \AA\right)$, as anticipated. In addition to the changes of the $\mathrm{N}-\mathrm{N}$ and $\mathrm{B}-\mathrm{N}$ bond lengths, the formation of $[1]^{--}$is accompanied by a substantial planarization of the system: the B atom is virtually in the plane of the ligand (displacement $<0.09 \AA$ for both $[\mathbf{1 a}]^{0^{--}}$and $[\mathbf{1 f}]^{{ }^{--}}$) and the unhindered $N$-Ph substituents become coplanar with the formazanate backbone. The slightly larger boron displacement in $[\mathbf{1 c}]^{--}(0.376 \AA)$ is due to an asymmetric interaction between the $\mathrm{Na}^{+}$cation and the $\mathrm{F}$ atoms (2.383(4) and 2.419(4) ̊̊) (Fig. 4).

The metrical parameters of each of the (formazanate)boron fragments in the para-phenylene linked compound $[\mathbf{1 j}]^{\cdot 2-}$ are similar to that in $[\mathbf{1 a}]^{--}$. These data suggest that $[\mathbf{1 j}]^{-2-}$ is best represented as two nearly-independent $\left[\mathrm{LBF}_{2}\right]^{]^{--}}$units, and a significant quinoidal contribution to the structure of the phenylene linker can be excluded. ${ }^{27}$

EPR spectroscopy for the radical anions $[\mathbf{1}]^{--}$shows broad, featureless resonances at $g \sim 2$, indicative of ligand-based radicals. While related organic verdazyl radicals show hyperfine interactions with the $\mathrm{N}$ nuclei, ${ }^{24,28}$ these are absent in the boron systems studied here. DFT calculations (see the ESI $\dagger$ ) suggest that the hyperfine coupling constants in $[\mathbf{1 a}]^{--}$are indeed smaller for the boron compounds reported here than those in organic analogues. Additionally, hyperfine interactions with the boron/fluorine nuclei are present in the compounds $[\mathbf{1} \mathbf{a}]^{--}$, which accounts for the broad signal with

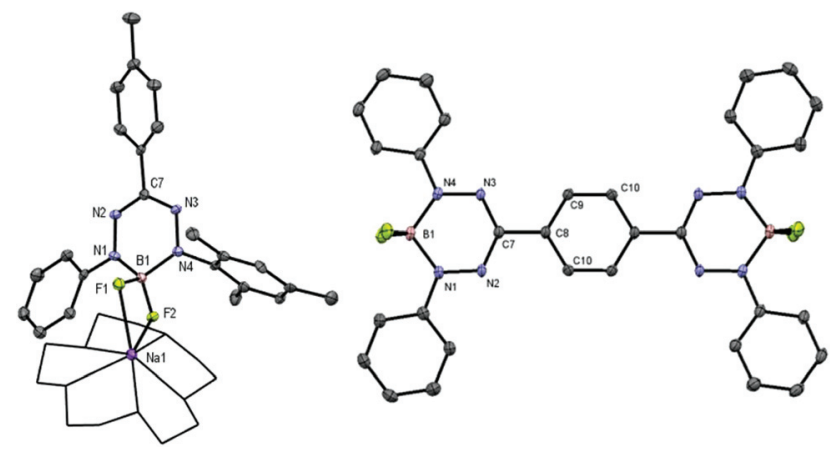

Fig. 4 Molecular structures of $\left[\mathrm{Na}(15-\text { crown-5) }]^{+}[1 \mathrm{c}]^{--}\right.$(left) and $\left[\mathrm{Cp}_{2}{ }_{2} \mathrm{Co}\right]_{2}^{+}[1 \mathrm{j}]^{\cdot 2-}$ (right) showing $50 \%$ probability ellipsoids; cations in the latter omitted for clarity. unresolved hyperfine interactions. The phenylene-linked systems $[\mathbf{1 j}]^{\cdot 2-}$ and $[\mathbf{1 k}]^{\cdot 2-}$ are diradicals similar to linked bis (verdazyl) radicals that have been reported, ${ }^{26,29}$ but in contrast to these purely organic systems our boron-based diradicals do not show zero-field splitting in their EPR spectra. This implies that the spin centres behave independently, effectively leading to $S=1 / 2$ behaviour without intramolecular electronic coupling $(J \sim 0) .{ }^{30}$ EPR spectra were collected in MeTHF/DMSO glass in the range between 5 and $40 \mathrm{~K}$ to evaluate the spin ground state of these compounds (Fig. S1 in the ESI†). Even though the absence of zero-field splitting indicates little or no electronic coupling, for the para-phenylene linker the signal intensity decreases upon cooling to $5 \mathrm{~K}$. This suggests the two radical centres to be anti-ferromagnetically coupled $(J<0)$ leading to a singlet biradical ground-state. For the metaphenylene linked compound $[\mathbf{1 k}]^{\cdot 2-}$, the signal broadens upon cooling but its intensity does not change significantly and a conclusive assignment of the electronic ground-state cannot be made. DFT calculations for both systems (see the ESI $\dagger$ ) agree with the VT EPR data that $[\mathbf{1 j j}]^{-2-}$ has a singlet biradical ground state. On the other hand, $[\mathbf{1 k}]^{\cdot 2-}$ is calculated to have a triplet ground state, which is in line with meta-phenylene linked bis(verdazyl) radicals reported in the literature. ${ }^{26}$

\section{Optical properties of the radical anions [1] $]^{-}$}

UV/Vis absorption spectroscopy of compounds $[1]^{\cdot-}$ shows two absorption bands in the visible range of the spectrum (see Table S3 in the ESI + ). One of these is shifted to lower energy (up to $716 \mathrm{~nm}$ for $[\mathbf{1 a}]^{--}$, Fig. 5) in comparison to the neutral precursors and is indicative of the presence of a formazanate ligand in the radical dianionic form $\left(\mathrm{L}^{\cdot 2-}\right) .^{18-20}$ We were interested to evaluate the influence of the redox-state of the compounds on their emission properties, and thus emission spectra of $[\mathbf{1 a}]^{\cdot-}$ were collected. Regardless of the excitation wavelength, the compound was only very weakly emissive and the observed spectrum indicates that $\lambda_{\mathrm{em}}$ is identical to that of the neutral precursor 1a. Based on this, we conclude that a small amount of decomposition to $\mathbf{1 a}$ is responsible for the observed spectrum, and the radical anions $[\mathbf{1}]^{--}$are non-emissive.

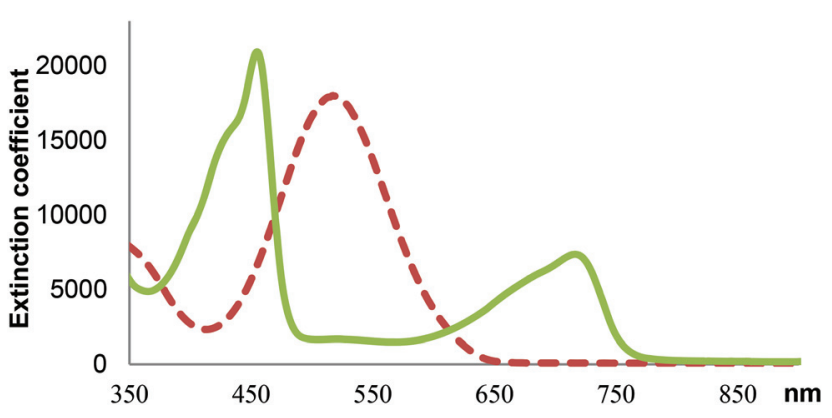

Fig. 5 UV-Vis absorption spectrum of compounds 1a (dotted red line) and $[1 \mathrm{a}]^{--}$(green line) in THF solution. 


\section{Theoretical calculations}

We have performed calculations in which the ground- and excited-states structures were respectively determined with DFT and Time-Dependent DFT (TD-DFT), whereas the transition energies were obtained with both TD-DFT and SOS-CIS (D) model, corrected for solvent effects (see the $\mathrm{ESI}^{\dagger}$ for details). This approach was shown previously to be adequate for fluoroborate complexes. ${ }^{31}$ In order to demonstrate the ability of this selected theoretical level in reproducing the structure, properties and electronic absorption spectra of formazanate boron complexes, systems $\mathbf{1 a}$ and $\left[\mathrm{Cp}_{2} \mathrm{Co}\right]^{+}[\mathbf{1 a}]^{\cdot-}$ have been chosen as representative examples. Inspection of the theoretically determined structure of $\mathbf{1 a}$, shows that the $\mathrm{B}$ atom is displaced with respect to the formazanate backbone, as indicated by the dihedral angle $(\mathrm{B} 1, \mathrm{~N} 1, \mathrm{~N} 2, \mathrm{~N} 3)$ of $16.29^{\circ}$. Moreover, the DFT-computed $\mathrm{C}-\mathrm{N}, \mathrm{N}-\mathrm{N}$ and $\mathrm{B}-\mathrm{N}$ bond lengths of the neutral 1a system are $1.340 \AA$, $1.286 \AA$ and $1.562 \AA$, respectively, showing electron delocalization along the chelating formazanate ligand. These values match well their experimental counterparts, though theory undershoots the $\mathrm{N}-\mathrm{N}$ bond length (Table 1). We have determined the optimal structure of the lowest singlet excited-state as well. It shows a nearly perfectly planar core with a $(\mathrm{B} 1, \mathrm{~N} 1, \mathrm{~N} 2, \mathrm{~N} 3)$ dihedral of $0.03^{\circ}$. In the excited-state, the computed $\mathrm{C}-\mathrm{N}, \mathrm{N}-\mathrm{N}$ and $\mathrm{B}-\mathrm{N}$ bond lengths attain $1.345 \AA$, $1.320 \AA$ and $1.567 \AA$, respectively, indicating a strong elongation of the $\mathrm{N}-\mathrm{N}$ bonds. These significant geometrical changes are consistent with the sizeable Stokes shifts that have been measured experimentally (see Table 1). Passing to the theoretically determined ground-state structure of the $[\mathbf{1 a}]^{--}$radical anion, large structural changes are also observed, in agreement with the experimental trends. Theory correctly predicts a significant planarization of the boron atom with respect to the plane of the formazanate ligand, resulting in a dihedral angle (B1,N1,N2,N3) value of $4.93^{\circ}$, much smaller than in 1a. Moreover, the experimentally observed elongation of the $\mathrm{N}-\mathrm{N}$ bond and the simultaneous shortening of the $\mathrm{B}-\mathrm{N}$ bond upon passing from neutral to radical anionic forms is also qualitatively reproduced by the theoretical calculations. Indeed, DFT foresees that the former goes from $1.286 \AA$ to $1.343 \AA$ and the latter from $1.562 \AA$ to $1.543 \AA$. To investigate the importance of the counterion, we have also optimized the 1:1 $\left[\mathrm{Cp}_{2} \mathrm{Co}\right]^{+}[1 \mathrm{a}]^{\circ-}$ complex, and obtained similar trends but quite different values, i.e., the dihedral is $9.34^{\circ}$, the N-N bond lengths are $1.342 \AA$ and $1.347 \AA$, whereas the $\mathrm{B}-\mathrm{N}$ distances are $1.539 \AA$ and $1.541 \AA$. It has to be noted that while in the solid-state it is in principle possible to observe changes in the planarity of the two phenyl substituents with respect to the central ring upon reduction of $\mathbf{1 a}$, in the theoretical liquid-phase calculations the essentially free rotation of the phenyl rings makes analogous comparisons less relevant. Clearly, DFT allows a reasonable determination of the ground-state equilibrium geometries of formazanate boron complexes.

In order to access the predictive capability of our model in reproducing the electronic absorption spectra of the neutral formazanate boron complexes, we have determined the vertical transition energies of all $11 \mathbf{1 x}[\mathbf{x}=\mathbf{a}, \mathbf{b} . .$.$] compounds in$ Table 1 and the obtained results are listed in Table 4 . We note that the chosen theoretical level, SOS-CIS(D), can nicely reproduce both the absolute experimental values and the trends upon substitution whereas TD-DFT overestimates the transition energies, as expected. ${ }^{31}$ For the full set of compounds, the mean signed error is $-4.7 \mathrm{~nm}$ and the mean absolute error is $15.1 \mathrm{~nm}$ when SOS-CIS(D) is applied. Clearly, these values are rather small. At the same time, the linear correlation coefficient relating theoretical and experimental values is large (0.97).

Let us now turn to the radical anions $[\mathbf{1 a}]^{\cdot-}$, the experimentally recorded UV-Vis spectra of both $\mathbf{1 a}$ and its radical anionic form in THF are shown in Fig. 5. One clearly notes the emergence of two bands in the visible range for the latter structure. Indeed, using TD-DFT, we computed two intense bands at $595 \mathrm{~nm}$ and $399 \mathrm{~nm}$ for $[\mathbf{1 a}]^{--}$which nicely surround the $463 \mathrm{~nm}$ values computed for 1a at the same level of theory. This fits well with the experimental trends. Indeed, the experiment reveals that the lowest-energy band of the neutral precursor 1a is significantly redshifted by $c a .198 \mathrm{~nm}$ upon passing to the radical anion, whereas theory underestimates the redshift $(132 \mathrm{~nm})$. For the second band, the experimental blueshift compared to the main band of $1 \mathrm{a}$ is $c a .-59 \mathrm{~nm}$, and theory provides $-64 \mathrm{~nm}$. Test calculations performed with the $\left[\mathrm{Cp}_{2} \mathrm{Co}\right]^{+}[\mathbf{1 a}]^{\cdot-}$ complex demonstrated that the counter-ion has a rather marginal impact on these variations.

In Fig. 6 the occupied-virtual molecular orbital (MO) pairs that characterise the most intense theoretically determined electronic transitions for both $\mathbf{1 a}$ and $\mathbf{1 a}^{--}$are shown. For $\mathbf{1 a}$ the lowest state can be mainly ascribed to a HOMO-LUMO transition, as expected. The pictures of the electron density redistribution that accompanies photoexcitation show that reduction of the neutral 1a compound does not change the nature of the transition (of HOMO to SOMO nature in $\mathbf{1 a}^{\cdot-}$ ) involved in the lowest-energy band of the absorption spectrum but merely shifts its position, in agreement with the experimental suggestion. Indeed, for both $\mathbf{1 a}$ and $\mathbf{1 a}^{\mathbf{*}}$ the lowestenergy transition is characterized by withdrawal of electron

Table 4 Experimental and theoretical wavelengths of maximum intensity for the absorption bands of systems [1x]. We show both the TD-DFT values and their SOS-CIS(D) counterparts

\begin{tabular}{llll}
\hline & $\begin{array}{l}\lambda_{\max }^{\text {TD-DF }} \\
(\mathrm{nm})\end{array}$ & $\begin{array}{l}\lambda_{\max }^{\text {SOS-CIS(D) }} \\
(\mathrm{nm})\end{array}$ & $\begin{array}{l}\lambda_{\max }^{\text {Exp }} \\
(\mathrm{nm})\end{array}$ \\
\hline 1a & 463 & 543 & 517 \\
1b & 418 & 485 & 473 \\
1c & 417 & 462 & 464 \\
1d & 445 & 501 & 482 \\
1e & 420 & 451 & 460 \\
1f & 400 & 434 & 431 \\
1g & 407 & 400 & 414 \\
1h & 414 & 486 & 502 \\
1i & 373 & 412 & 428 \\
1j & 469 & 545 & 523 \\
1k & 463 & 535 & 508
\end{tabular}




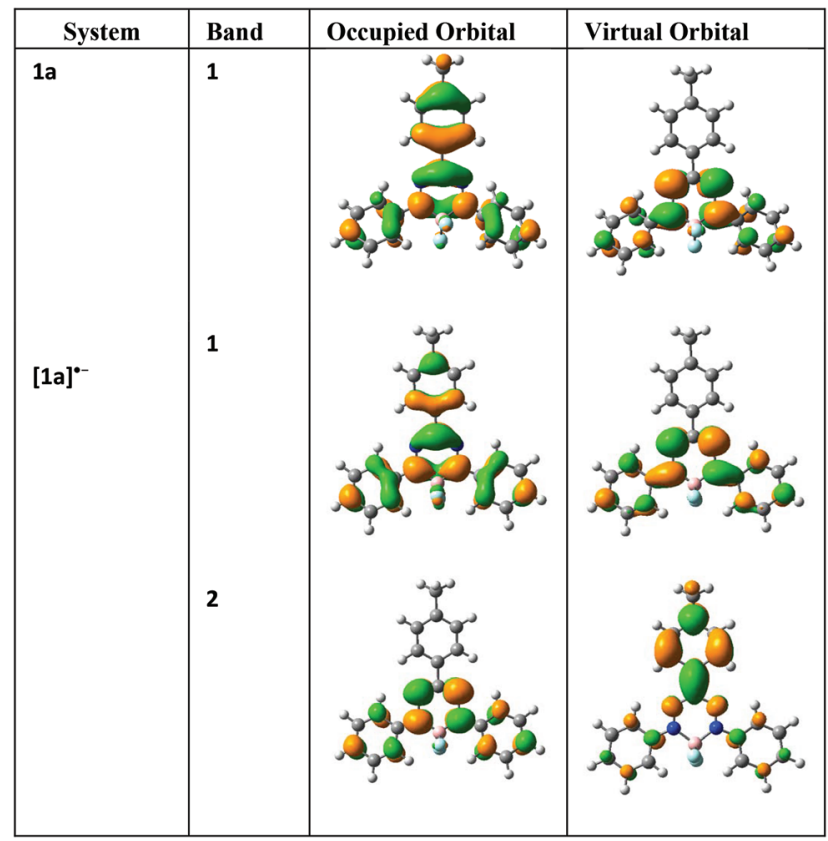

Fig. 6 Occupied-virtual molecular orbital (MO) pairs that characterize the most intense theoretically determined electronic transitions for compounds $1 \mathrm{a}$ and $1 \mathrm{a}^{\cdot-}$. The numbering of the bands is based on the experimentally determined absorption spectra for both systems. Contour threshold: 0.03 a.u.

density from the $p$-tolyl group and its redistribution on the rest of the system. In contrast, the long wavelength band of $1 \mathrm{a}^{\cdot-}$ is characterized by electron density withdrawal from the formazanate-containing ring and two phenyls to the $p$-tolyl group.

\section{Conclusions}

We have prepared a series of (formazanate)boron difluoride complexes and evaluated their structural, electrochemical and luminescent properties. The neutral compounds (1) show an intense absorption band in the visible range, which TD-DFT calculations confirm to be due to electronic transitions $(\pi \rightarrow$ $\left.\pi^{*}\right)$ within the ligand. Evaluation of their luminescence properties shows large Stokes shifts across the series, albeit with low quantum yields. In case of the cyano-substituted formazans, the emission wavelength may be further increased by coordination of a Lewis acid (as shown for $\mathbf{1 h B C F}$ ). For a representative series of compounds, the 1-electron reduction products $\left(\mathbf{1}^{\cdot-}\right)$ were characterised, which show two absorption maxima in the visible that occur at both higher and lower energy than in the neutral precursor. Theoretical calculations indicate that, similar to the experimentally verified structures of 1-electron reduction products, photochemical excitation to the lowest singlet excited state results in large structural reorganization/planarization following the partial population of the $\mathrm{N}-\mathrm{N} \pi^{*}$-orbitals. Due to the non-emissive nature of the radical anions $\mathbf{1}^{\cdot-}$, the formazanate boron difluoride compounds presented here allow for redox-switching of their lumi- nescent properties, and may find application in sensing and imaging applications.

\section{Acknowledgements}

E. O. is grateful to the Netherlands Organisation for Scientific Research (NWO) for a Veni grant. D. J. acknowledges the European Research Council (ERC) for financial support in the framework of a starting grant (Marches-278845). A. C. thanks the ERC (Marches-278845) for his postdoctoral grant. This research used resources of the GENCI-CINES/IDRIS, of the CCIPL, and of a local Troy cluster. We thank Prof. Wesley Browne for access to spectroscopic facilities and help with quantum yield determinations and Prof. Bas de Bruin for VT-EPR data.

\section{Notes and references}

1 (a) A. Martin, R. D. Moriarty, C. Long, R. J. Forster and T. E. Keyes, Asian J. Org. Chem., 2013, 2, 763-778; (b) K. Sreenath, Z. Yuan, J. R. Allen, M. W. Davidson and L. Zhu, Chem. - Eur. J., 2015, 21, 867-874; (c) A. Yamada, Y. Hiruta, J. Wang, E. Ayano and H. Kanazawa, Biomacromolecules, 2015, 16, 2356-2362; (d) P. Agarwal, B. J. Beahm, P. Shieh and C. R. Bertozzi, Angew. Chem., Int. Ed., 2015, 54, 11504-11510.

2 (a) T. W. Hudnall and F. P. Gabbai, Chem. Commun., 2008, 4596-4597; (b) M. V. Kuperman, S. V. Chernii, M. Y. Losytskyy, D. V. Kryvorotenko, N. O. Derevyanko, Y. L. Slominskii, V. B. Kovalska and S. M. Yarmoluk, Anal. Biochem., 2015, 484, 9-17.

3 (a) A. M. Prokhorov, T. Hofbeck, R. Czerwieniec, A. F. Suleymanova, D. N. Kozhevnikov and H. Yersin, J. Am. Chem. Soc., 2014, 136, 9637-9642; (b) X. Cao, J. Miao, M. Zhu, C. Zhong, C. Yang, H. Wu, J. Qin and Y. Cao, Chem. Mater., 2015, 27, 96-104; (c) L. Yao, S. Zhang, R. Wang, W. Li, F. Shen, B. Yang and Y. Ma, Angew. Chem., Int. Ed., 2014, 53, 2119-2123.

4 (a) S. D. Topel, G. T. Cin and E. U. Akkaya, Chem. Commun., 2014, 50, 8896-8899; (b) T. Yogo, Y. Urano, Y. Ishitsuka, F. Maniwa and T. Nagano, J. Am. Chem. Soc., 2005, 127, 12162-12163.

5 (a) S. Erten-Ela, M. D. Yilmaz, B. Icli, Y. Dede, S. Icli and E. U. Akkaya, Org. Lett., 2008, 10, 3299-3302; (b) A. Mishra, M. K. R. Fischer and P. Bäuerle, Angew. Chem., Int. Ed., 2009, 48, 2474-2499.

6 V. Ntziachristos, J. Ripoll, L. V. Wang and R. Weissleder, Nat. Biotechnol., 2005, 23, 313-320.

7 (a) S. J. Farley, D. L. Rochester, A. L. Thompson, J. A. K. Howard and J. A. G. Williams, Inorg. Chem., 2005, 44, 9690-9703; (b) W. Qin, M. Baruah, M. Van der Auweraer, F. C. De Schryver and N. Boens, J. Phys. Chem. A, 2005, 109, 7371-7384.

8 D. Frath, J. Massue, G. Ulrich and R. Ziessel, Angew. Chem., Int. Ed., 2014, 53, 2290-2310. 
9 (a) A. Loudet and K. Burgess, Chem. Rev., 2007, 107, 48914932; (b) G. Ulrich, R. Ziessel and A. Harriman, Angew. Chem., Int. Ed., 2008, 47, 1184-1201; (c) N. Boens, V. Leen and W. Dehaen, Chem. Soc. Rev., 2012, 41, 1130-1172.

10 (a) J. Rosenthal and S. J. Lippard, J. Am. Chem. Soc., 2010, 132, 5536-5537; (b) J.-J. Shie, Y.-C. Liu, Y.-M. Lee, C. Lim, J.-M. Fang and C.-H. Wong, J. Am. Chem. Soc., 2014, 136, 9953-9961; (c) C. Cheng, N. Gao, C. Yu, Z. Wang, J. Wang, E. Hao, Y. Wei, X. Mu, Y. Tian, C. Ran and L. Jiao, Org. Lett., 2015, 17, 278-281.

11 (a) T. Lundrigan, S. M. Crawford, T. S. Cameron and A. Thompson, Chem. Commun., 2012, 48, 1003-1005; (b) G. Duran-Sampedro, I. Esnal, A. R. Agarrabeitia, J. Bañuelos Prieto, L. Cerdán, I. García-Moreno, A. Costela, I. Lopez-Arbeloa and M. J. Ortiz, Chem. - Eur. J., 2014, 20, 2646-2653; (c) T. Lundrigan, T. S. Cameron and A. Thompson, Chem. Commun., 2014, 50, 7028-7031; (d) A. B. More, S. Mula, S. Thakare, N. Sekar, A. K. Ray and S. Chattopadhyay, J. Org. Chem., 2014, 79, 10981-10987.

12 A. Martin, C. Long, R. J. Forster and T. E. Keyes, Chem. Commun., 2012, 48, 5617-5619.

13 J. C. Er, M. K. Tang, C. G. Chia, H. Liew, M. Vendrell and Y.-T. Chang, Chem. Sci., 2013, 4, 2168-2176.

14 (a) F. P. Macedo, C. Gwengo, S. V. Lindeman, M. D. Smith and J. R. Gardinier, Eur. J. Inorg. Chem., 2008, 3200-3211; (b) R. Yoshii, A. Hirose, K. Tanaka and Y. Chujo, J. Am. Chem. Soc., 2014, 136, 18131-18139; (c) R. Yoshii, A. Hirose, K. Tanaka and Y. Chujo, Chem. - Eur. J., 2014, 20, 8320-8324; (d) S. M. Barbon, V. N. Staroverov, P. D. Boyle and J. B. Gilroy, Dalton Trans., 2014, 43, 240250.

15 J. F. Araneda, W. E. Piers, B. Heyne, M. Parvez and R. McDonald, Angew. Chem., Int. Ed., 2011, 50, 1221412217.

16 (a) C. Yu, L. Jiao, P. Zhang, Z. Feng, C. Cheng, Y. Wei, X. $\mathrm{Mu}$ and E. Hao, Org. Lett., 2014, 16, 3048-3051; (b) I.-S. Tamgho, A. Hasheminasab, J. T. Engle, V. N. Nemykin and C. J. Ziegler, J. Am. Chem. Soc., 2014, 136, 5623-5626; (c) Q. Huaulmé, A. Mirloup, P. Retailleau and R. Ziessel, Org. Lett., 2015, 17, 2246-2249.

17 (a) G. Nawn, R. McDonald and R. G. Hicks, Inorg. Chem., 2013, 52, 10912-10919; (b) G. Nawn, S. R. Oakley,
M. B. Majewski, R. McDonald, B. O. Patrick and R. G. Hicks, Chem. Sci., 2013, 4, 612-621.

18 J. B. Gilroy, M. J. Ferguson, R. McDonald, B. O. Patrick and R. G. Hicks, Chem. Commun., 2007, 126-128.

19 (a) M.-C. Chang, T. Dann, D. P. Day, M. Lutz, G. G. Wildgoose and E. Otten, Angew. Chem., Int. Ed., 2014, 53, 4118-4122; (b) M.-C. Chang, P. Roewen, R. TraviesoPuente, M. Lutz and E. Otten, Inorg. Chem., 2015, 54, 379388.

20 M. C. Chang and E. Otten, Chem. Commun., 2014, 50, 7431-7433.

21 (a) S. M. Barbon, J. T. Price, P. A. Reinkeluers and J. B. Gilroy, Inorg. Chem., 2014, 53, 10585-10593; (b) S. M. Barbon, P. A. Reinkeluers, J. T. Price, V. N. Staroverov and J. B. Gilroy, Chem. - Eur. J., 2014, 20, 11340-11344; (c) S. M. Barbon, V. N. Staroverov and J. B. Gilroy, J. Org. Chem., 2015, 80, 5226-5235.

22 M. Hesari, S. M. Barbon, V. N. Staroverov, Z. Ding and J. B. Gilroy, Chem. Commun., 2015, 51, 3766-3769.

23 R. R. Maar, S. M. Barbon, N. Sharma, H. Groom, L. G. Luyt and J. B. Gilroy, Chem. - Eur. J., 2015, 21, 1558915599.

24 D. Matuschek, S. Eusterwiemann, L. Stegemann, C. Doerenkamp, B. Wibbeling, C. G. Daniliuc, N. L. Doltsinis, C. A. Strassert, H. Eckert and A. Studer, Chem. Sci., 2015, 6, 4712-4716.

25 S. M. Barbon, J. T. Price, U. Yogarajah and J. B. Gilroy, RSC Adv., 2015, 5, 56316-56324.

26 J. B. Gilroy, S. D. J. McKinnon, P. Kennepohl, M. S. Zsombor, M. J. Ferguson, L. K. Thompson and R. G. Hicks, J. Org. Chem., 2007, 72, 8062-8069.

27 L. K. Montgomery, J. C. Huffman, E. A. Jurczak and M. P. Grendze, J. Am. Chem. Soc., 1986, 108, 6004-6011.

28 R. G. Hicks, in Stable Radicals, John Wiley \& Sons, Ltd, 2010, pp. 245-279.

29 (a) K. Mukai, N. Azuma, H. Shikata and K. Ishizu, Bull. Chem. Soc. Jpn., 1970, 43, 3958-3960; (b) R. M. Fico, M. F. Hay, S. Reese, S. Hammond, E. Lambert and M. A. Fox, J. Org. Chem., 1999, 64, 9386-9392.

30 M. Abe, Chem. Rev., 2013, 113, 7011-7088.

31 B. Le Guennic and D. Jacquemin, Acc. Chem. Res., 2015, 48, 530-537. 